\title{
Evaluation of long-term surgical treatment outcomes of thoraco-lumbar spinal fractures - follow-up period of over 10 years
}

\author{
Robert Węgłowski ${ }^{1, A-F}{ }^{\oplus}$, Paweł Polak ${ }^{2, C, E-F \oplus}$, Piotr Piech ${ }^{3, B-D \oplus}$ \\ ${ }^{1}$ University of Physical Education in Warsaw, branch in Biała Podlaska, Poland \\ ${ }^{2}$ Centre of Oncology of the Lublin Region St. Jana z Dukli, Poland \\ ${ }^{3}$ Department of Human Anatomy, Medical University, Lublin, Poland \\ A - Research concept and design, B - Collection and/or assembly of data, C - Data analysis and interpretation, \\ $D$ - Writing the article, E - Critical revision of the article, F- Final approval of article
}

Węgłowski R, Polak P, Piech P. Evaluation of long-term surgical treatment outcomes of thoraco-lumbar spinal fractures - follow-up period of over 10 years. Ann Agric Environ Med. 2021; 28(2): 339-344. doi: 10.26444/aaem/120051

\begin{abstract}
Introduction and objective. Agricultural accidents often result in spinal injuries, particularly in fractures of the thoracolumbar spine. Surgical treatment of thoraco-lumbar fractures continues to comprise a major medical problem. The aim of this study was to assess and compare the long-term effects of surgical treatments of thoracic and lumbar spinal fractures treated with transpedicular stabilization, combined with posterior interbody spinal fusion (PLIF, also known as spondylodesis) or Daniaux reconstruction.

Materials and method. A retrospective analysis was conducted on 66 patients with a thoracic or lumbar spinal fracture (Th10-L3) type A in the AO classification system, operated in 2000-2005. All patients underwent a short segment transpedicular stabilization, which in 36 patients was combined with posterior interbody spinal fusion, and in 30 other patients combined with Daniaux reconstruction. Radiological assessment was performed based on X-ray imaging. A lateral X-ray image of the spine was used to measure the vertebral wedging angle of the fractured vertebrae, the height ratio of the anterior to posterior vertebral body, and the angle of segmental kyphotic deformation. Subjective long-term assessment of the patient was conducted using the Oswestry Instability Score. The results were analyzed for statistical significance.

Results. In both groups, similar improvements in all measured parameters were observed. Despite all patients losing some of the correction in the long-term, this loss was significantly smaller following Daniaux reconstruction.

Conclusions. Spinal stabilization combined with vertebral reconstruction allows for long-term and improved treatment results for thoraco-lumbar fracture than posterior interbody spinal fusion (spondylodesis).
\end{abstract}

Key words

PLIF, agricultural accidents, thoraco-lumbar spinal fracture, Daniaux reconstruction

\section{INTRODUCTION}

Agricultural accidents often result in spinal injuries, particularly in fractures of the thoraco-lumbar sections of the spine $[1,2]$. The necessity to operate on unstable spinal fractures is non-controversial; however, the choice of treatment method continues to cause disagreement $[3,4,5]$. The course of treatment is determined not only by the type of fracture, the degree of narrowing of the spinal canal and the presence of neurological symptoms, but also by angular spinal flexion and loss of vertebral height $[6,7]$.

Most authors point out the necessity of reproducing the correct height of the fractured vertebral body as well as the functional spinal unit, thus leading to restoration of spinal balance. Despite the appearance of several novel reconstruction methods, none are free of drawbacks and do not fully prevent secondary recurrent deformations $[7,8,9,10]$. Analysis of the literature does not allow for the determination of which method is more favourable, or effectively prevents recurrent deformations, especially a long time after surgery $[4,7,11,12,13,14]$.

Address for correspondence: Robert Węgłowski, University of Physical Education in Warsaw, branch in Biała Podlaska, Poland

E-mail: r.weglowski@wp.pl

Received: 26.01.2020; accepted: 03.04.2020; first published: 15.04 .2020

\section{OBJECTIVES}

The aim of the study was to assess and compare the long-term results of surgical treatment of thoraco-lumbar fractures, accompanied either by posterior interbody spinal fusion (PLIF) or Daniaux reconstruction.

\section{MATERIALS AND METHOD}

A retrospective analysis was conducted on 66 patients operated on between 2000-2005 due to traumatic spinal fractures sustained due to agricultural accidents. The average follow-up time was 13.2 years, and not less than 10 years. The mean age of the patients was 34 years and ranged between $15-52$ years. The majority of the patients (48) were male. The assessment was conducted on patients with fractures in vertebral bodies ranging from Th10 - L3, where the most commonly fractured vertebral bodies were those transitioning between thoracic kyphosis and lumbar lordosis (83.5\%), with the most common being L1 (53\%). Only type A fractures in the OA classification system, without accompanying neurological symptoms, and in which spinal support was not removed, were qualified into the study. 36 patients underwent PLIF, while 30 patients underwent vertebral reconstruction following the Daniaux method (Tab. 1). 
Table 1. Fracture type and treatment method

\begin{tabular}{lcccc}
\hline AO & No. of patients & $\%$ & $\begin{array}{c}\text { Daniaux } \\
\text { (No. of patients) }\end{array}$ & $\begin{array}{c}\text { PLIF } \\
\text { (No. of patients) }\end{array}$ \\
\hline A 1.3 & 10 & 15.2 & 5 & 5 \\
\hline A 2.2 & 3 & 4.5 & 2 & 1 \\
\hline A 2.3 & 28 & 42.4 & 12 & 16 \\
\hline A 3.1 & 12 & 18.2 & 6 & 6 \\
\hline A 3.2 & 7 & 10.6 & 3 & 4 \\
\hline A3.3 & 6 & 9.1 & 2 & 4 \\
\hline
\end{tabular}

In all patients, a short segment transpedicular stabilization (including the vertebra above and below the fracture) was performed. Following screw insertion, a wide laminectomy was performed, which also aided in controlling the anterior wall of the spinal canal, which is necessary to remove dislodged bone splinters of the fractured vertebral body or a damaged intervertebral disc. Next, the fracture was repositioned by distraction and reclination of the vertebra. Reconstruction of the anterior wall of the spinal canal was achieved by insertion using a mallet, or removing dislodged bone fragments after previously gently moving the spinal cord to both sides. At this stage of the operation, frequent bleeding from the damaged venous plexus on the posterior wall of the fractured vertebral body was found and controlled.

PLIF was performed by using a specialized set of instruments. A metal sleeve was embedded into the space between the dural sac (which was moved aside), below the root of the spinal nerve and at the height of the intervertebral disc, through which two canals of $10 \mathrm{~mm}$ diameter were drilled on either side of the spinal cord, reaching almost to the anterior longitudinal ligament. A small spoon was used to remove remaining fragments of the intervertebral disc and to scarify the endplate of the neighboring vertebral bodies. Bone grafts previously taken from the iliac crest were inserted into the space left by the removal of the intervertebral disc. PLIF was only performed on the superior level of the fractured vertebral body.

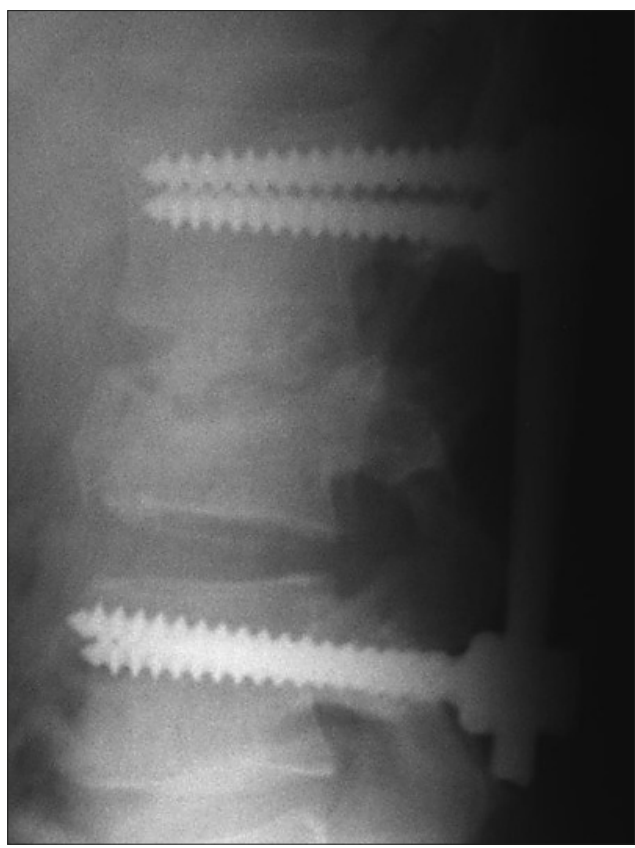

Figure 1. L2 fracture after surgery. PLIF reconstruction
VBDR is the insertion of bone grafts through the base of the arch of the fractured vertebral body using a specialized tunnel. Holes with a diameter of $4-8 \mathrm{~mm}$ were drilled at the bases of the arches of the fractured vertebral body. A curved mallet was inserted through the holes, and used to raise the deformed superior and lowered inferior wall of the vertebral body. Once the funnel was inserted, the spongy osseous tissue missing from the vertebral body was replaced with bone grafts.

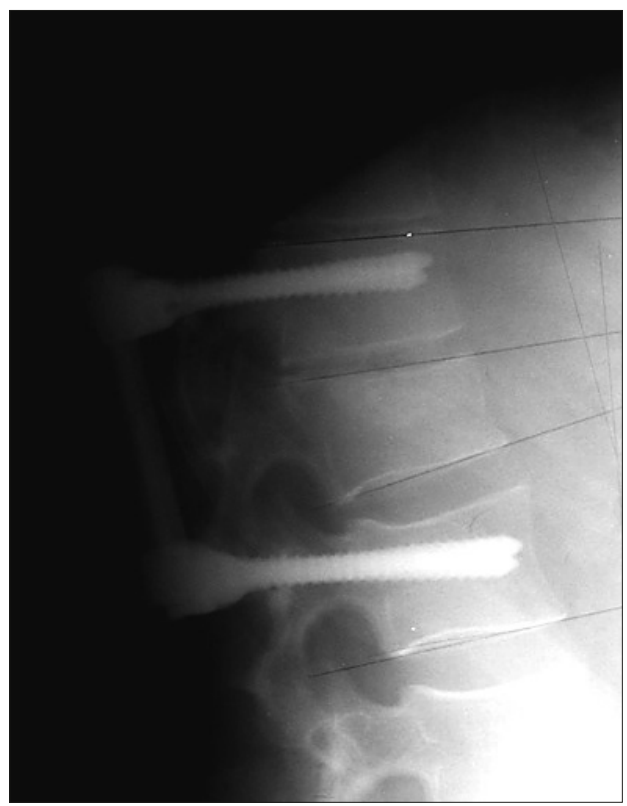

Figure 2. L1 fracture. Shaft reconstruction according to Daniaux

Radiological assessment of the deformations was conducted using X-ray imaging prior to surgery, then after surgery but prior to verticalizing the patient (between 2-4 days after surgery), by using the last image available during the followup period (after 10-15 years). A side-view spinal X-ray image was used on which the vertebral wedging angle, the height ratio of the anterior to posterior wall of vertebral body, and the segmental kyphotic deformation angle were measured. Figure 1 shows a diagram of these measurements (Fig. 3).

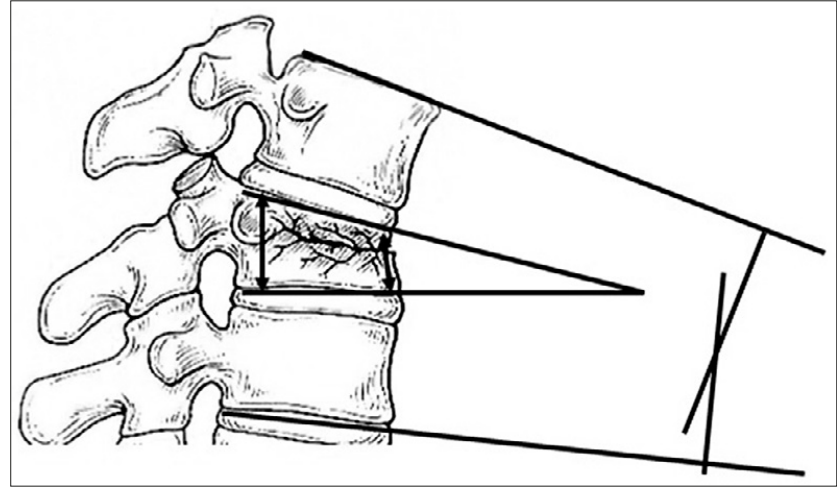

Figure 3. Diagram of measurements used

A subjective assessment of the patient's long-term state was conducted using the Oswestry Instability Score [15]. Quantitative data were recorded in a Microsoft Office Excel Spreadsheet and statistically analyzed using Statistica for 
Windows. The arithmetic mean, minimum and maximum values were used. Statistical significance was calculated using Friedman's ANOVA and the Mann-Whitney U-test. The threshold for statistical significance was set at $\mathrm{p}<0.05$.

\section{RESULTS}

Analysis of the treatment outcomes focused on the radiological outcomes. In both groups, an improvement of the vertebral wedging angle was achieved. Better treatment outcomes were recorded following VBDR treatment. In both groups, a loss of correction was observed in the long-term; however, in the patient group that underwent VBDR, this loss was significantly smaller $(\mathrm{p}<0.05)$ (Tab. 2$)$.

Analogically, the best outcome of vertebral body reconstruction, calculated as the ratio of the height of the anterior to the posterior vertebral body, was also achieved following VBDR surgery, where an improvement of the $\mathrm{AB} /$ $\mathrm{PB}$ segment of 0.17 was achieved, more than double that achieved by using the PLIF method. The difference was statistically significant. In both groups the correction did not turn out to be permanent, and was found to be 0.06 . In the PLIF patient group, the size of the vertebral body deformity in the long-term proved to be almost identical to the deformity calculated prior to surgery (Tab. 3).

Analysis of the segmental angle found a lower correction following PLIF. In the long-term, a loss of correction was noted; however, this was smaller following VBDR treatment $(\mathrm{p}<0.05)$ (Tab. 4). Despite the loss of correction, a destabilization of the fusion only occurred in 2 patients (4.8\%) and manifested as a broken screw (one VBDR patient) and a broken beam connecting 2 screws (one patient - PLIF).

Table 2. Analysis of vertebral wedging angle

\begin{tabular}{|c|c|c|c|c|}
\hline \multirow[b]{2}{*}{$\begin{array}{l}\text { Vertebral } \\
\text { angle }\end{array}$} & \multicolumn{2}{|c|}{ VBDR } & \multicolumn{2}{|c|}{ PLIF } \\
\hline & $\begin{array}{l}\text { Average } \\
\text { min.-max. } \\
\text { st.dev. }\end{array}$ & $\begin{array}{c}\text { correction + } \\
\text { loss of } \\
\text { correction - }\end{array}$ & $\begin{array}{l}\text { Average } \\
\text { min.-max. } \\
\text { st.dev. }\end{array}$ & $\begin{array}{l}\text { correction + } \\
\text { loss of } \\
\text { correction - }\end{array}$ \\
\hline Before & $17.53^{\circ}\left(3^{\circ}-32^{\circ}\right)$ & & $18.08^{\circ}\left(4^{\circ}-34^{\circ}\right)$ & \\
\hline procedure & $6.36^{\circ}$ & & $6.69^{\circ}$ & \\
\hline $\begin{array}{l}\text { After } \\
\text { procedure }\end{array}$ & $\begin{array}{c}10.00^{\circ}\left(1^{\circ}-23^{\circ}\right) \\
5.59^{\circ}\end{array}$ & $+7.53^{\circ}$ & $\begin{array}{c}13.94^{\circ}\left(1^{\circ}-31^{\circ}\right) \\
6.57^{\circ}\end{array}$ & $+4.14^{\circ}$ \\
\hline $\begin{array}{l}\text { Long-term } \\
\text { result }\end{array}$ & $\begin{array}{c}12.90^{\circ}\left(1^{\circ}-26^{\circ}\right) \\
5.80^{\circ}\end{array}$ & $-2.90^{\circ}$ & $\begin{array}{c}16.03^{\circ}\left(3^{\circ}-35^{\circ}\right) \\
5.58^{\circ}\end{array}$ & $-2.09^{\circ}$ \\
\hline$P$ & $<0.0$ & & $<0.0$ & \\
\hline
\end{tabular}

Table 3. Analysis of height ratio of the anterior to posterior vertebral body

\begin{tabular}{lcccc}
\hline $\begin{array}{l}\text { Ratio of anterior } \\
\text { body height to } \\
\text { posterior body } \\
\text { height }\end{array}$ & $\begin{array}{c}\text { Average } \\
\text { min.-max. st.dev. }\end{array}$ & $\begin{array}{c}\text { correction }+ \\
\text { loss of } \\
\text { correction - }\end{array}$ & $\begin{array}{c}\text { Average } \\
\text { min.-max. } \\
\text { st.dev. }\end{array}$ & $\begin{array}{c}\text { correction }+ \\
\text { loss of } \\
\text { correction - }\end{array}$ \\
\cline { 2 - 6 } Before procedure & $0.62(0.29-0.89) 0.12$ & & $\begin{array}{c}0.61(0.36- \\
0.93) 0.14\end{array}$ & \\
\hline After procedure & $0.80(0.50-0.97) 0.11$ & $-0,18$ & $\begin{array}{c}0.69(0.38- \\
0.97) 0.13\end{array}$ & -0.08 \\
\hline Long-term result & $0.73(0.44-0.96) 0.11$ & $+0,07$ & $\begin{array}{c}0.62(0.29- \\
0.93) 0.11\end{array}$ & 0.07 \\
\hline$P$ & $<0.0001$ & & \multicolumn{2}{c}{$<0.0015$} \\
\hline
\end{tabular}

Table 4. Analysis of segmental angle

\begin{tabular}{lcccc}
\hline \multirow{2}{*}{$\begin{array}{l}\text { Segmental } \\
\text { angle }\end{array}$} & $\begin{array}{c}\text { Average } \\
\text { min.-max. st.dev. }\end{array}$ & $\begin{array}{c}\text { correction }+ \\
\text { loss of } \\
\text { correction - }\end{array}$ & $\begin{array}{c}\text { Average } \\
\text { min.-max. st.dev. }\end{array}$ & $\begin{array}{c}\text { Porrection }+ \\
\text { loss of } \\
\text { correction - }\end{array}$ \\
\cline { 2 - 5 } $\begin{array}{l}\text { Before } \\
\text { procedure }\end{array}$ & $\begin{array}{c}16.10^{\circ}\left(2^{\circ}-37^{\circ}\right) \\
7.71^{\circ}\end{array}$ & $\begin{array}{c}18.50^{\circ}\left(2^{\circ}-36^{\circ}\right) \\
8.53^{\circ}\end{array}$ & \\
\hline After & $9.27^{\circ}\left(2^{\circ}-25^{\circ}\right)$ & $+6.83^{\circ}$ & $\begin{array}{c}13.00^{\circ}\left(2^{\circ}-30^{\circ}\right) \\
7.37^{\circ}\end{array}$ & $+5.50^{\circ}$ \\
procedure & $5.38^{\circ}$ & & $7.37^{\circ}$ & \\
\hline Long-term & $12.73^{\circ}\left(3^{\circ}-36^{\circ}\right)$ & $-3.46^{\circ}$ & $18.53^{\circ}\left(1^{\circ}-47^{\circ}\right)$ & $-5.53^{\circ}$ \\
result & $5.92^{\circ}$ & & $12.31^{\circ}$ & \\
\hline $\mathrm{P}$ & $<0.00001$ & & $<0.00207$ &
\end{tabular}

Additionally, a Mann-Whitney U-test showed a statistically significant difference between the 2 treatment groups across all parameters measured in the post-operative period, as well as in the long-term for the vertebral angle, ratio of anterior body height to posterior body height, and the segmental angle $(\mathrm{p}<0.05)$. No significant differences were found for any parameters measured prior to surgery, demonstrating the uniformity of the 2 groups.

Table 5. Statistical differences between VBDR and PLIF

\begin{tabular}{lc}
\hline SA before & $p$ \\
\hline AB/PB after & 0.25 \\
\hline VA before & 0.76 \\
\hline SA after & 0.66 \\
\hline AB/PB after & 0.03 \\
\hline VA after & 0.001 \\
\hline SA after & 0.01 \\
\hline AB/PB after & 0.05 \\
\hline VA after & 0.01 \\
\hline
\end{tabular}

Improved results were also achieved following VBDR treatment when analyzing the Oswestry Instability Score (Tab. 6).

Table 6. Oswestry Instability Score

\begin{tabular}{lcc}
\hline Result & Daniaux & PLIF \\
\hline $0 \%-20 \%$ & 19 & 17 \\
\hline $21 \%-40 \%$ & 10 & 15 \\
\hline $41 \%-60 \%$ & 1 & 1 \\
\hline average & $19.93 \%$ & $23.38 \%$ \\
\hline$p$ & & $<0.05$ \\
\hline
\end{tabular}

\section{DISCUSSION}

Thoraco-lumbar fractures are some of the most common spinal fractures. Despite surgical recommendations being significantly expanded, these fractures continue to present a major surgical problem $[3,16,17]$. In choosing the optimal treatment, reviews summarizing clinical experiences can prove to be very helpful, even though reports in the literature are usually retrospective. 
While most authors acknowledge the necessity of operating on unstable spinal fractures, the choice of surgical method remains controversial $[3,4,5,18,19]$. Many parameters are considered, such as the type of fracture, stability, the degree of narrowing of the spinal canal, the degree of angular flexion of the spine, and neurological symptoms [4,7,20,21]. Due to the lack of a unified classification system for spinal fractures, the treatment of similar injuries may take different courses at various clinics.

In planning an operation, it should be borne in mind that it should fulfil the correct conditions, so that the treatment results are satisfactory not only directly after the procedure, but also in the long-term. Most importantly, treatment should aim to decompress the nervous structures, followed by reproducing the axis of the spine, ensuring its stability and conditions allowing for bone fusion; it must also recreate the frontal spinal column. It is also important to allow fast and full mobilization of the patient.

When assessing the long-term results of surgical treatment for thoraco-lumbar spinal fractures, an open question remains: how to prevent the loss of correction of the fractured vertebral bodies or secondary kyphotic curvature of the spine.

The most popular treatment method for thoraco-lumbar fractures is posterior transpedicular stabilization $[19,20$, $22,23]$. This ensures internal spinal stabilization and gives resistance to flexion, rotational and extension forces. It additionally immobilizes the short segment of the spine, corrects the spinal axis and reproduces the height of the frontal vertebral body. However, the stabilization alone, without reconstructive procedures around the spine, is unfortunately doomed to fail due to the loss of corrective effects or a loosening of the fusion $[4,24,25,26,27]$.

Reconstruction of fractured vertebral bodies by filling empty spaces with bone grafts allows for the restoration of vertebral body height. Reclination alone of the spinal body without reconstruction of its height is impermanent because kyphotic deformation can reoccur [8]. Proponents of this method believe that reconstructing the vertebral body can effectively restore its height, and a small loss of correction in the long-term demonstrates its permanent remodeling $[8,9,10]$. Opponents, on the other hand, are trying to prove that this method does not prevent a loss of correction and with time can lead to slow, spontaneous spondylodesis with kyphotic curvature [26, 27, 28, 29].

A retrospective analysis was conducted of 66 patients with thoraco-lumbar fractures sustained through agricultural accidents, in which a short-segment stabilization with spinal body reconstruction or posterior interbody spondylodesis were performed. In this study, the best correction of the fractured vertebral body and Cobb's angle was achieved following a spinal body reconstruction procedure with bone grafts introduced through the base of the vertebral arch. Following surgery, a correction of the deformed vertebral body we achieved by an average of $7.53^{\circ}$, compared to $4.14^{\circ}$ following posterior interbody spondylodesis. A relatively smaller improvement was achieved when analyzing the Cobb's angle analogically, from $6.38^{\circ}-5.50^{\circ}$. However, in the longterm a recurrence of the deformity was observed; however, better results were achieved following reconstruction of the fractured vertebral body. In the long-term, the loss of correction of the fractured vertebral body was $2.90^{\circ}$ following VBDR 0 and $2.09^{\circ}$ following a PLIF procedure. Analogously, the loss of correction of Cobb's angle was $3.46^{\circ}$ and $5.53^{\circ}$, respectively

In the literature, Zang reports a perfect correction of a broken vertebral body from $23.7 \%-95.8 \%$. The average observation period was 17.2 months [30]. Li compared results in 2 groups, between a control group (45 patients) and a spinal body reconstruction group (75 patients). The followup period was $27-70$ months. In the long-term, the height ratio of the vertebral body was $93.7 \%$ in the reconstruction group and 66.3\% in the control group [31]. Qinliang Li [32] also achieved an improvement in the correction of Cobb's angle and vertebral body height over a 2 -year follow-up period. However, it should be emphasized that the authors additionally used a transpedicular screw inserted into the fractured vertebral body with the aim of achieving better correction and durability. Alanay divided patients into 2 groups. In the first group, the spine was stabilized and bone grafts were inserted into the vertebral body through the base of the arch, while in the second group, only spinal stabilization was performed. In the long-term, a smaller loss of anterior vertebral body height of the fractured vertebral body was achieved following reconstruction with bone grafts; however, the results were not statistically significant. The average follow-up time was 24 months [4].

Opponents of the method have observed a recurrence of vertebral body deformation. In a study by Liljenqvist and Mommsen [13], the loss of correction was found to be $10.1^{\circ}$. In addition to the loss of correction, the authors also observed changes in the height of intervertebral discs. When assessing the long-term effects, the conceiver of the method, Daniaux [8], also observed a loss of correction by $10.4^{\circ}$. A similar observation was noted by Aebiin which a loss of correction of $3.6^{\circ}$ was observed, representing 29\%) [11].

Several authors indicate the necessity of interbody spondylodesis, which should prevent the loss of correction in the long-term. An indisputable argument in favour of interbody arthrodesis is that it is the best way to ensure longterm spinal stability. Without performing an arthrodesis, all forms of stabilization can be prone to failure over time. As bone fusion proceeds, these bones take on progressively greater loads affecting the spine. Once the fusion has redeveloped, the loads are transmitted mainly through the bone, and only partially through the implant. However, some authors question the necessity of performing this procedure, believing that it prevents the loss of correction of kyphotic spinal deformation. They also indicate the increased risk of developing degeneration of the neighboring motion segments, and emphasize the persistence of pain symptoms in the area of graft collection. A separate issue raised by some authors is also the problem of stenosis of the spinal canal resulting from spondylodesis.

In his retrospective studies, Qian [33] concluded that patients who did not undergo spinal immobilization experienced a significantly greater loss of correction and had worse functionality outcomes. Sanderson, in his study of 24 patients who did not undergo interbody spondylodesis, [23] found an average loss of correction of $8^{\circ}$ after a follow-up period of 3.1 years. In prospective studies conducted on 58 patients by Wang, [7], a greater loss was found of correction of the segmental angle in patients without spondylodesis than in those with it. However, he did not find any statistically significant differences between the groups with and without immobilization. LaMajda [34] also reported positive results of 
monosegmental stabilization combined with spondylodesis. In a 2-year follow-up period, he reported an improvement of the vertebral body angle from $23.6^{\circ}$ to $13.9^{\circ}$. However, the cited authors believe that performing a spondylodesis is essential. They also point out that the reason for the loss of correction in patients without spondylodesis is an additional loss of height in the damaged intervertebral disc [7, 23].

In their studies, the opponents of spondylodesis point out a recurrence of deformities after the procedure has been performed. In a prospective randomized study conducted on 73 patients, Dai [14] found no conclusive evidence differentiating stabilization with or without spondylodesis. Knop [15] used Cobb's angle to measure treatment outcomes after performing an interbody spondylodesis, achieving a post-surgery correction of $11.8^{\circ}$. Unfortunately, there was a partial loss of correction in the long-term, with an average loss of $7.8^{\circ}$. The consequences of undergoing a spondylodesis are a separate issue, and the long-term effects are frequently discussed in international literature. These studies indicate that there is a lack of a significant link between back pain and patient age, post-surgical follow-up time, and the extent of spondylodesis.

In a study conducted on 27 patients, Wang [35] noted a recurrence of kyphotic spinal deformity following the removal of a spinal stabilizer, without the recurrence of deformity of the fractured vertebral body. The author also noted changes in the height of the intervertebral disc, where a loss of height was found following removal of the stabilizer, indicating that stabilization protects against loss of height only temporarily.

\section{CONCLUSIONS}

Reconstruction of the anterior wall of a fractured vertebral body by filling holes left by cancellous bone with bone grafts provides the chance for permanent correction; when inserted into the anterior $2 / 3$ rds of the vertebral body they promote healing of fractures and ensure their permanent restoration. Unfortunately, posterior interbody spondylodesis does not guarantee the long-term maintenance of spinal correction or absence of kyphotic curvature, but when these outcomes are achieved, the results are permanent.

\section{REFERENCES}

1. Mathur N, Jain S, Kumar N, Srivastava A, Purohit N, Patni A. Spinal cordinjury: scenario in an Indian state. Spinal Cord. 2015; 53: 349-52. https://doi.org/10.1038/sc.2014.153

2. Rastogi D, Meena S, Sharma V, Singh GK. Causality of injury and outcome in patientsadmitted in major trauma center in North India. Int J Crit IIln Inj Sci. 2014; 4: 298-302. https://doi.org/10.4103/22295151.147523

3. Kaneda P, Taneichi H, Abumi K, Hashimoto T, Satoh S, Fujiya M. Anterior decompression and stabilization with the Kaneda device for thoracolumbar burst fractures associated with neurological deficits. J Bone Joint Surg Am. 1997; 79: 69-83. https://doi.org/10.2106/00004623199701000-00008

4. Alanay A, Acaroglu E, Yazici M, Oznur A, Surat A. Short-segment pedicle instrumentation of thoracolumbar burst fractures: Does transpedicular intracorporeal grafting prevent early failure? 2001; 26: 213-217. https://doi.org/10.1097/00007632-200101150-00017

5. Chen H, Wang W, Li K, Chen T. Biomechanical effects of the body augumenter for reconstruction of the vertebral body. Spine. 2004; 29: 382-387. https://doi.org/10.1097/01.brs.0000139308.65813.70
6. Briem D, Lehmann W, Ruecker A, Windolf J, Rueger J, Linhart W. Factors influencing the quality of life after burst fractures of the thoracolumbar transition. Arch Orthop Trauma Surg. 2004; 124: 461-468. https://doi.org/10.1007/s00402-004-0710-5

7. Wang S, Ma H, Liu C, Yu W, Chang M, Chen T. Is fusion necessary for surgical treated burst fractures of the thoracolumbar and lumbar spine?: A prospective, randomized study. Spine. 2006; 31: 2646-2652. https://doi.org/10.1097/01.brs.0000244555.28310.40

8. Daniaux H, Seykora P, Genelin A. Application of posterior plating and modification in thoraco-lumbar spine injuries. Indication, techniques and results. Spine. 1991; 16: 125-133. https://doi.org/10.1097/00007632199103001-00018

9. Jacobs R, Casey M. Surgical management of thoracolumbar spinal injuries: general principles and controversial considerations. Clin Orthop Relat Res. 1984; 189: 22-31.

10. Crawford R, Ashin G. Fixation of thoracolumbar fractures with Dick fixator: the influence of transpedicular bone grafting. Eur Spine J. 1994; 3: 45-51. https://doi.org/10.1007/bf02428316

11. Aebi M, Etter C, Kehl T, Thalgott J. Stabilization of the lower thoracic and lumbar spine with the internal spinal skeletal fixation system: indications, techniques, and first results of treatment. Spine. 1987; 12: 544-551. https://doi.org/10.1097/00007632-198707000-00007

12. Liljenquist U, Mommen U. Die operative Behandlung thoracolumbalen Wirbelsäule-verletzungen mit dem Fixateur interne und transpedikuläre Spongiosaplastik. Unfallchirurg. 1995; 21: 30-36. https:// doi.org/10.1007/bf02588348

13. Dai L, Jiang L, Jiang S. Posterior short-segment fixation with or without fusion for thoracolumbar burst fractures. A five to seven-year prospective randomized study. J Bone Joint Surg Am. 2009; 91: 10331041. https://doi.org/10.2106/jbjs.h.00510

14. Knop C, Bastian L, Lange U, Blauth M. Transpedicular fusion of the thoraco-lumbar junction. Clinical, radiographic and CT results. Orthopade. 1999; 28: 703-713. https://doi.org/10.1007/s001320050400

15. Fairbank JC, Pynsent PB. The Oswestry Distability Index. Spine. 2000; 25: 2940-2952. https://doi.org/10.1097/00007632-200011150-00017

16. Müller U, Berlemann U, Sledge J, Schwarzenbach O. Treatment of thoracolumbar burst fractures without neurologic deficit by indirect reduction and posterior instrumentation: bisegmental stabilization with monosegmental fusion. Eur Spine J. 1999; 8: 284-289. https://doi. org/10.1007/s005860050175

17. Sasso P, Best N, Reilly T, McGuire R. Anterior-only stabilization of three-column thoracolumbar injuries. J Spinal Disord Tech. 2005; 18: 7-14. https://doi.org/10.1097/01.bsd.0000137157.82806.68

18. Alvine G, Swain J, Asher M, Burton D. Treatment of thoracolumbar burst fractures with variable screw placement or Isola instrumentation and arthrodesis: case series and literature review. J Spinal Disord Tech. 2004; 17: 251-264. https://doi.org/10.1097/01.bsd.0000095827.98982.88

19. Kim BG, Dan JM, Shin DE. Treatment of thoracolumbar fracture. Asian Spine J. 2015; 9(1): 133-46. https://doi.org/10.4184/asj.2015.9.1.133

20. Wood KB, Buttermann GR, Phukan R, Harrod CC, Mehbod A, Shannon B, et al. Operative compared with nonoperative treatment of a thoracolumbar burst fracture without neurological deficit: a prospective randomized study with follow-up at sixteen to twentytwo years. J Bone Joint Surg Am. 2015; 97: 3-9. https://doi.org/10.2106/ jbjs.n.00226

21. Wood K, Bohn D, Mehbod A. Anterior versus posterior treatment of stable thoracolumbar burst fractures without neurologic deficit: a prospective, randomized study. J Spinal Disord Tech. 2005; 18: 15-23. https://doi.org/10.1097/01.bsd.0000132287.65702.8a

22. Parker J, Lane J, Karaikovic E, Gaines R. Successful short-segment instrumentation and fusion for thoracolumbar spine fractures: a consecutive 4 1/2-year series. Spine. 2000; 25: 1157-1170. https://doi. org/10.1097/00007632-200005010-00018

23. Sanderson P, Fraser R, Hall D, Cain C, Osti O, Potter G. Short segment fixation of thoracolumbar burst fractures without fusion. Eur Spine J. 1999; 8: 495-500. https://doi.org/10.1007/s005860050212

24. McLain R, Sparling E, Benson D. Early failure of short-segment pedicle instrumentation of thoracolumbar fractures. A preliminary report. J Bone Joint Surg Am. 1993; 75: 162-167. https://doi. org/10.2106/00004623-199302000-00002

25. Moon M, Choi W, Moon Y, Kim Y, Moon J. Stabilisation of fractured thoracic and lumbar spine with Cotrel-Dubousset instrument. J Orthop Surg. 2003; 11: 59-66. https://doi.org/10.1177/230949900301100113

26. Ko SB, Lee SW. Result of posterior instrumentation without fusion in the management of thoracolumbar and lumbar unstable burst fracture. J Spinal Disord Tech. 2014; 27: 189-95. https://doi.org/10.1097/ bsd.0b013e31825bfc8e 
27. Jeon $\mathrm{CH}$, Lee YS, Youn SJ, Lee HD, Chung NS. Factors affecting postural reduction in posterior surgery for thoracolumbar burst fracture. J Spinal Disord Tech. 2015; 28(4): E225-30. https://doi.org/10.1097/ bsd.0000000000000208

28. Knop C, Fabian HF, Bastian L, Rosenthal H, Lange U, Zdichavsky M, et al. Fate of the transpedicular intervertebral bone graft after posterior stabilisation of thoracolumbar fractures. Eur Spine J. 2002; 11: 251-257. https://doi.org/10.1007/s00586-001-0360-Z

29. Leferink V, Zimmerman K, Veldhuis E, Veldhuis E, ten Vergert E, ten Duis H. Thoracolumbar spinal fractures: radiological results of transpedicular fixation combined with transpedicular cancellous bone graft and posterior fusion in 183 patients. Eur Spine J. 2001; 10: 517-523. https://doi.org/10.1007/s005860100319

30. Zhang J, Xiao B, Xu R, Zhao L, Ma W, Ruan Y. Analysis of safety and effect of the technique of reconstructing anterior and middle columns by single posterior approach. Zhongguo Gu Shang. 2009; 22(7): 494-7.
31. Li K, Hsieh C, Lee C, Chen T. Transpedicle body augumenter: a further step in treating burst fractures. Clin Orthop Relat Res. 2008; 466: 2555-6.

32. Qinliang L, Cai Y, Shichun L. Transpedicular bone grafting and pedicle screw fixation in injured vertebrae using a paraspinal approach for thoracolumbar fractures: a retrospective study. J Orthop Surg Res. 2016; 11: 115. https://doi.org/10.1186/s13018-016-0452-4

33. Qian B, Qiu Y, Wang B, Yu Y, Zhu Z. Effect of posterolateral fusion on thoracolumbar burst fractures. Chin J Traumatol. 2006; 9: 349-355.

34. La Maida GA, Ruosi C, Misaggi B. Indications for the monosegmental stabilization of thoraco-lumbar spine fractures. Int Orthop. 2019; 43: 169-176. https://doi.org/10.1007/s00264-018-4226-y

35. Wang X, Dai L, Xu H, Chi Y. Kyphosis recurrence after posterior shortsegment fixation in thoracolumbar burst fractures. J Neurosurg Spine. 2008; 8(3): 246-254. https://doi.org/10.3171/spi/2008/8/3/246 